\title{
Injection Molding of Ribbed Plastic Plates with a Superplastic Zn-22\% Al Sheet
}

\author{
S. Y. YANG and S. H. PARNG \\ Department of Mechanical Engineering, National Taiwan University, Taipei, Taiwan, R.O.C.
}

Received: April 10, 2000

Accepted: March 29, 2001

\begin{abstract}
This article presents the development of a hybrid process combining the forming of a superplastic zinc-aluminum sheet with injection molding. The product is a plastic part covered with a superplastic zincaluminum layer used mainly for electromagnetic interference (EMI) shielding. This hybrid process involves not only molding a plastic plate, but also forming a superplastic zinc-aluminum sheet with features such as ribs. This research observes the process of filling the cavity and forming the superplastic sheet with the aid of short-shot experiments. By understanding the molding and forming process, guidelines for process control will be derived. This research further investigates the moldability of SIM systems. To make satisfactory parts, sheet thickness, melt temperature, injection parameters, and other process parameters determine the "moldability" of a specific system. The first part of the moldability study is to identify the relative importance of these process parameters. Results show that melt temperature and injection pressure are the two most critical parameters. The second part of this moldability study is to develop the moldability diagrams based on the molding area on the plane of these two key parameters. Moldability diagrams are employed to evaluate the effects of sheet thicknesses and melt inlets. It is found that a thick sheet, high melt temperature, and an inlet providing short flow length improve moldability. (c) 2001 John Wiley \& Sons, Inc. Adv Polym Techn 20: 216-225, 2001
\end{abstract}




\section{Introduction}

$\mathbf{T}$ here are many ways to shield against electromagnetic interference (EMI); some are based on conductive housings, ${ }^{1-3}$ and others on nonconductive housings with surface plating of a conductive layer. Conductive housings are usually manufactured from plastic-based composites refined with stainless steel fibers or graphite fibers. Shielding effect is low and the screw suffers severe wear. Using another way, surface plating requires a secondary operation and is more costly than one-step molding of a filled system. ${ }^{4}$ Furthermore, scratches could reduce the effectiveness of shielding. ${ }^{5}$

Magnesium has emerged as an EMI shielding material for housings. ${ }^{6}$ It offers good EMI shielding and excellent heat dissipation; however, the process needs special machines and the yield is still low. Kimura et al. ${ }^{7}$ developed a process to manufacture a hybrid housing in which resin is injected with aluminum adhered to it. This aluminum/resin housing offers good EMI shielding with reasonable weight; however, the aluminum sheet only allows little deformation during this process. Most features, such as ribs and bosses in housings, will not be able to be molded with this design.

Superplastic materials exhibit high ductility under proper conditions. High superplastic ductility may be observed in materials with small grain size (usually $<10 \mu \mathrm{m}$ ), at high homologous temperature (at least $>0.5 T_{\mathrm{m}}$, where $T_{\mathrm{m}}$ is the absolute melting point), and processed under a limited range of strain rate. ${ }^{8}$ For instance, $\mathrm{Zn}-22 \% \mathrm{Al}$ is an excellent commercial superplastic material known for its low forming temperature, high strain rate sensitivity, and large tensile elongation. ${ }^{9}$ The highest elongations of $\mathrm{Zn}-22 \% \mathrm{Al}$ are found to be nearly $3000 \%$. Conventionally, superplastic sheets are formed by blow molding. The strain rates are between $10^{-3} \sim 10^{-1} \mathrm{~s}^{-1}$ during processing. ${ }^{10}$

This study reports on the attempts to form a superplastic zinc-aluminum sheet with plastic injection molding. The product is a plastic part covered with a zinc-aluminum layer, providing a continuous metal enclosure over plastic parts, either on the outside or inside surfaces, to prevent EMI. For definition purposes, the process of forming superplastic sheets by injection molding will be called superplastic injection molding (SIM) in this article. As illustrated in Figure 1, the SIM process includes five stages: (1) loading a tailored superplastic sheet in the mold; (2) closing the mold halves and preforming the superplastic sheet; (3) injecting plastic melt to fill the cavity while further forming the superplastic sheet at the same time; (4) packing; and (5) cooling.

The SIM process involves forming the superplastic sheet during cavity filling and packing. Conventional design guidelines for injection molding are not consistently applicable to the SIM process. Unknown rules for mold design reflect the state of the art of this new process, and long troubleshooting time will hinder the widespread use of this effective method.

To make better application of any new process, process observation and moldability investigations are helpful. Taking gas-assisted injection molding (GAIM) as an example, to understand the GAIM process, Lanvers, ${ }^{11}$ Zheng, ${ }^{12}$ Yamamoto, ${ }^{13}$ and Yang ${ }^{14}$ have performed flow visualization of the GAIM process with a glass-insert mold. Also, Yang et al. ${ }^{15}$ have extended the moldability diagram for conventional injection molding ${ }^{16}$ to the GAIM process. To understand this new SIM process, a series of partly molded parts are to be collected to indirectly observe the cavity filling and sheet forming processes with short-shot experiments.

As far as moldability of SIM is concerned, sensitivity of process parameters will be compared. The two most sensitive processing parameters, $\mathrm{A}$ and $\mathrm{B}$, will be identified. The moldability of a system is then defined based on a molding area on the plane of processing conditions $\mathrm{A}$ and $\mathrm{B}$, as shown in Figure 2. In conventional molding, the processing parameters, $\mathrm{A}$ and $\mathrm{B}$, are melt temperature and injection pressure. The molding area is bound by four curves. Outside the molding area, molded parts may contain defects. Above the top curve, the melt degrades thermally (defect 1); whereas below the bottom curve, the melt will not flow (defect 3). To the left of the molding area, the melt is too viscous to fill the mold at the applied pressure (defect 4). To the right of the molding area, injection pressure is high enough for the flash to occur (defect 2). Within the molding area bound by these four curves, a complete part can be molded in the specific system.

In brief, the aim of this work is to understand SIM by process observation and moldability investigation. Three objectives are addressed in this study: (1) to observe the sheet deformation during the SIM process in a mold for plates with ribs with the aid of short-shots; (2) to investigate the sensitivity and relative importance of processing parameters; and 


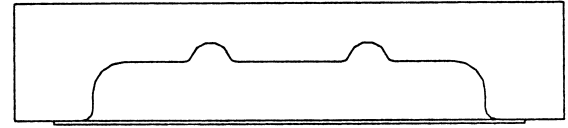

step 1 loading superplastic sheet

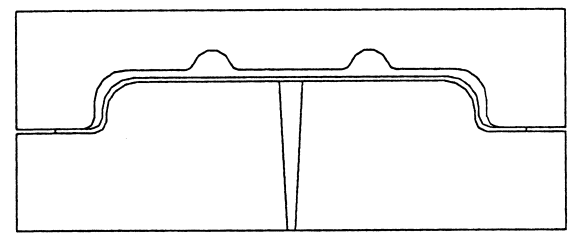

step 2 closing the mold and preforming the sheet

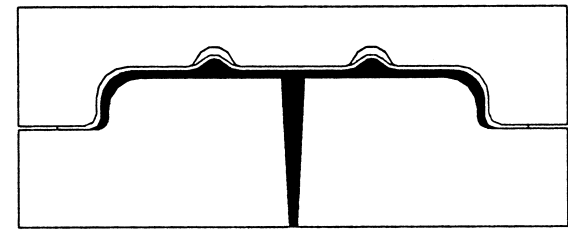

step 3 filling the cavity and forming the sheet

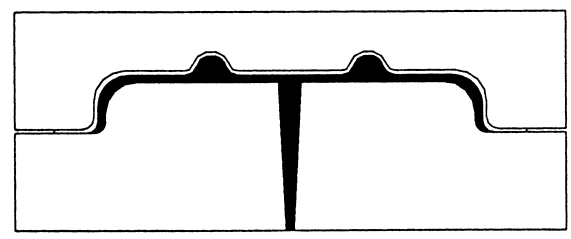

step 4 packing and cooling
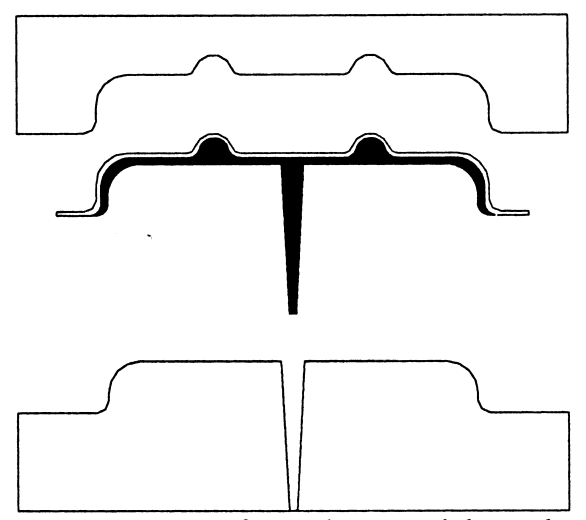

step 5 opening the mold and ejecting the part

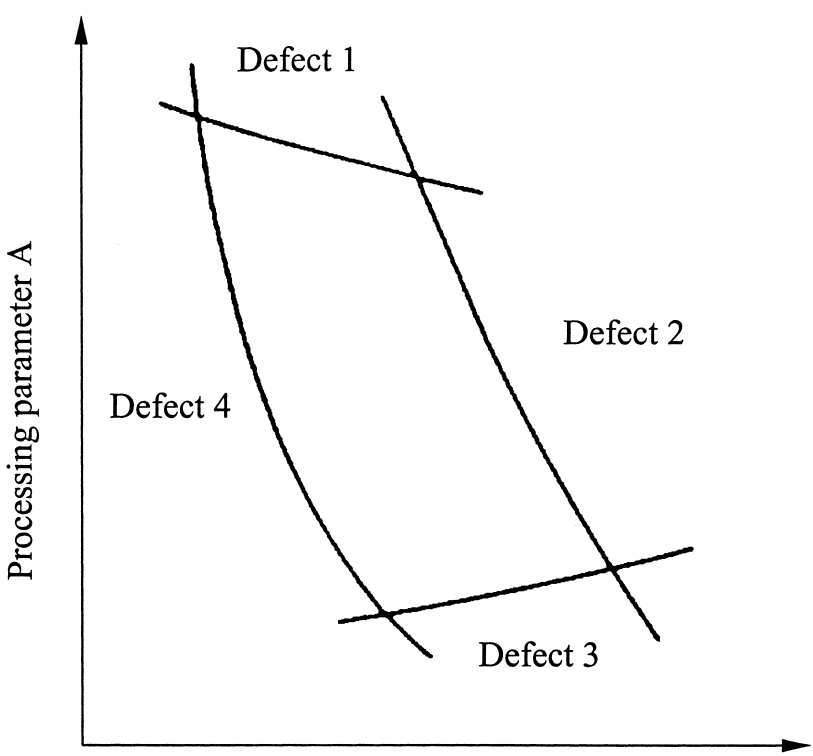

Processing parameter B

FIGURE 2. Schematics of the moldability diagrams for molding systems for injection molding (IM), parameters A-melt temperature and B-injection pressure; Defects: 1. degradation, 2. flash, 3. short-shot, 4. shortshot.

(3) to define the moldability diagram based on the most critical processing parameters for the SIM process.

\section{Experimental Setup}

\section{MATERIALS AND MOLDS}

The superplastic sheet used in this study is made of $\mathrm{Zn}-22 \% \mathrm{Al}$, manufactured by the Light Metals Laboratory of Ta-Tung University (Taipei, Taiwan). The mechanical behavior of the material is shown in Figure 3. ${ }^{17}$ The sheet thickness varies from 0.1 to $0.3 \mathrm{~mm}$. The SIM experiments are conducted on a

FIGURE 1. Schematics showing the process of superplastic injection molding (SIM), a hybrid process combining superplastic sheet forming with injection molding. 
50-ton injection-molding machine (Green Pax G-50, Taiwan), with a maximum injection pressure of 1960 bar and a maximum injection rate of $112 \mathrm{~cm}^{3} / \mathrm{s}$. An injection-grade polystyrene, 951N (TAI-TA, Taiwan), is used in this study.

Ribbed plastic plates 90-mm long, 20-mm wide, and 2-mm thick, covered with a layer of superplastic $\mathrm{Zn}-22 \% \mathrm{Al}$ sheet on the inner surface are to be molded in this study. Figure 4 shows the photograph of the part before degating and trimming. A deformed (ribbed) zinc-aluminum sheet encloses the bottom surface of the transparent PS part.

A mold is designed and constructed for SIM experiments. The mold is composed of two mold plates: a stationary mold plate and a movable mold plate. The stationary mold plate is shown in Figure $5 \mathrm{a}$. The corresponding insert is shown in Figure $5 \mathrm{~b}$. There are two possible melt entrances: inlets $\mathrm{A}$ and $B$. The flow length using inlet $A$ in the middle is shorter than that using inlet $B$ at the end. Only one inlet is used at a time. For process observation, inlet $\mathrm{B}$ is used; for moldability investigation, both inlets

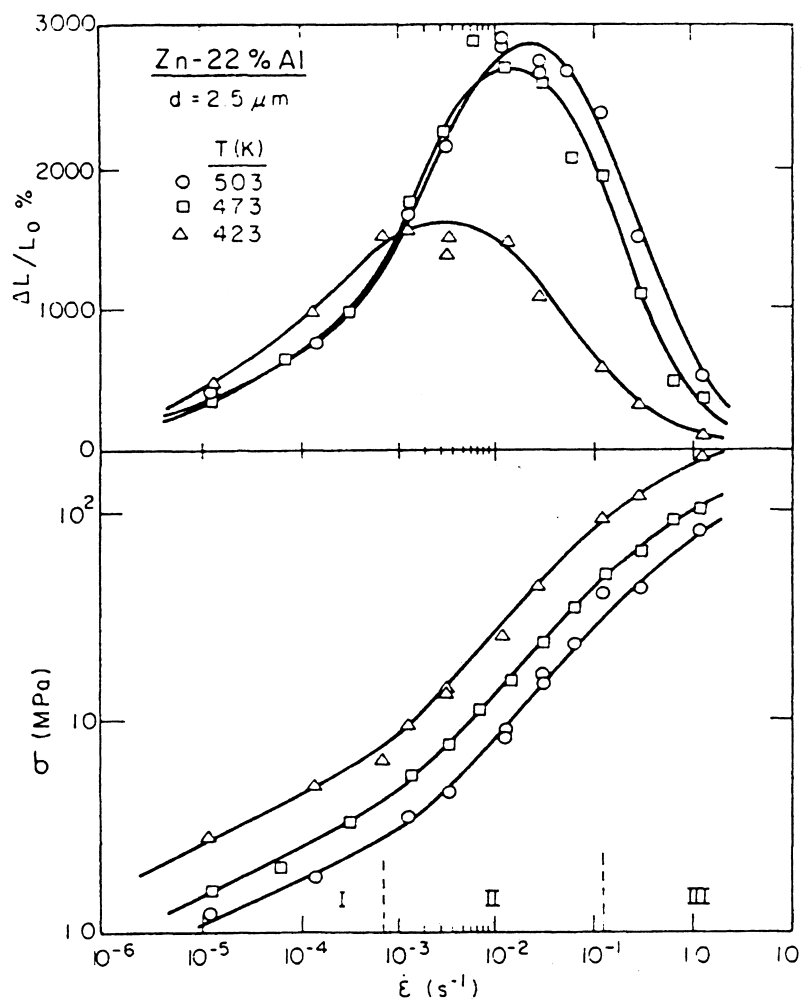

FIGURE 3. Mechanical behavior of superplastic Zn$22 \%$ Al material. The highest elongation (nearly 3000\%) can be obtained under proper processing conditions (Mohamed ${ }^{17}$ ).

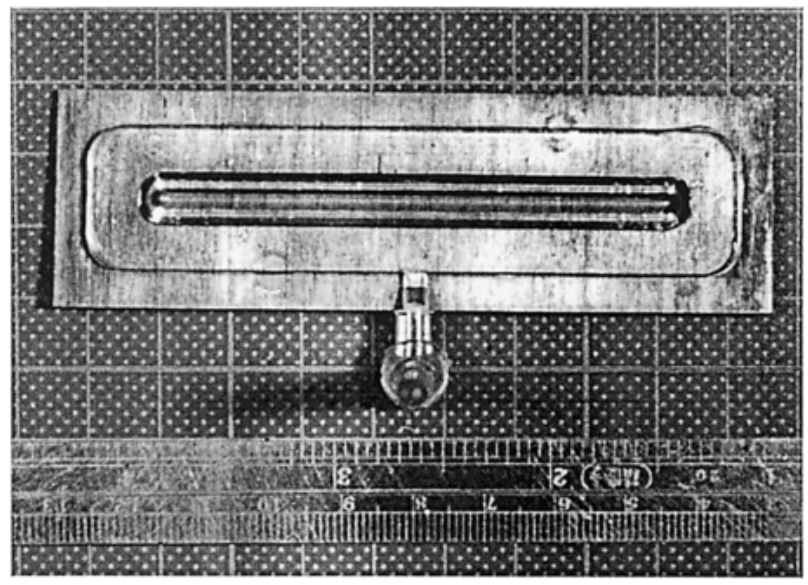

FIGURE 4. Photograph showing a SIM molded part before degating and trimming. Metal sheet encloses the bottom surface of the PS plate with rib.

$A$ and $B$ are used. The construction of the movable mold plate is similar to that of the stationary mold plate, except that there is no runner and the seat for the insert is $20-\mathrm{mm}$ deep. The inserts for the movable mold plate are shown in Figure 6. The dimension of the rib is $3 \mathrm{~mm}$ in radius.

The $\mathrm{Zn}-22 \% \mathrm{Al}$ sheet is first cut to $100-\mathrm{mm}$ long and $30-\mathrm{mm}$ wide. The sheet is then placed in the movable mold plate. After the mold is closed, the sheet is tightly clamped. Plastic melt is then injected to fill the cavity. As the melt proceeds, the sheet is deformed and the geometric feature, the rib, is formed as well. In this study, no adhesive is applied to the sheet.

\section{SHORT-SHOT EXPERIMENTS AND NUMERICAL FILLING SIMULATION}

To help understand the deformation of the zincaluminum sheet during the cavity filling process, a series of short-shots are obtained by injecting various melt weights. The deformed rib depths at three sections downstream of the gate, 20,50, and $80 \mathrm{~mm}$, are then measured and plotted as functions of shortshot percentages.

The sheet is $0.2 \mathrm{~mm}$ in thickness. Inlet B is used for its long flow length. Short-shot injection moldings are performed with the flowing processing conditions:

- Short-shot weights (\%): 36.7, 63.8, 76.4, 80.6, $86.4,88.2,91.8,97.3$ and 100 

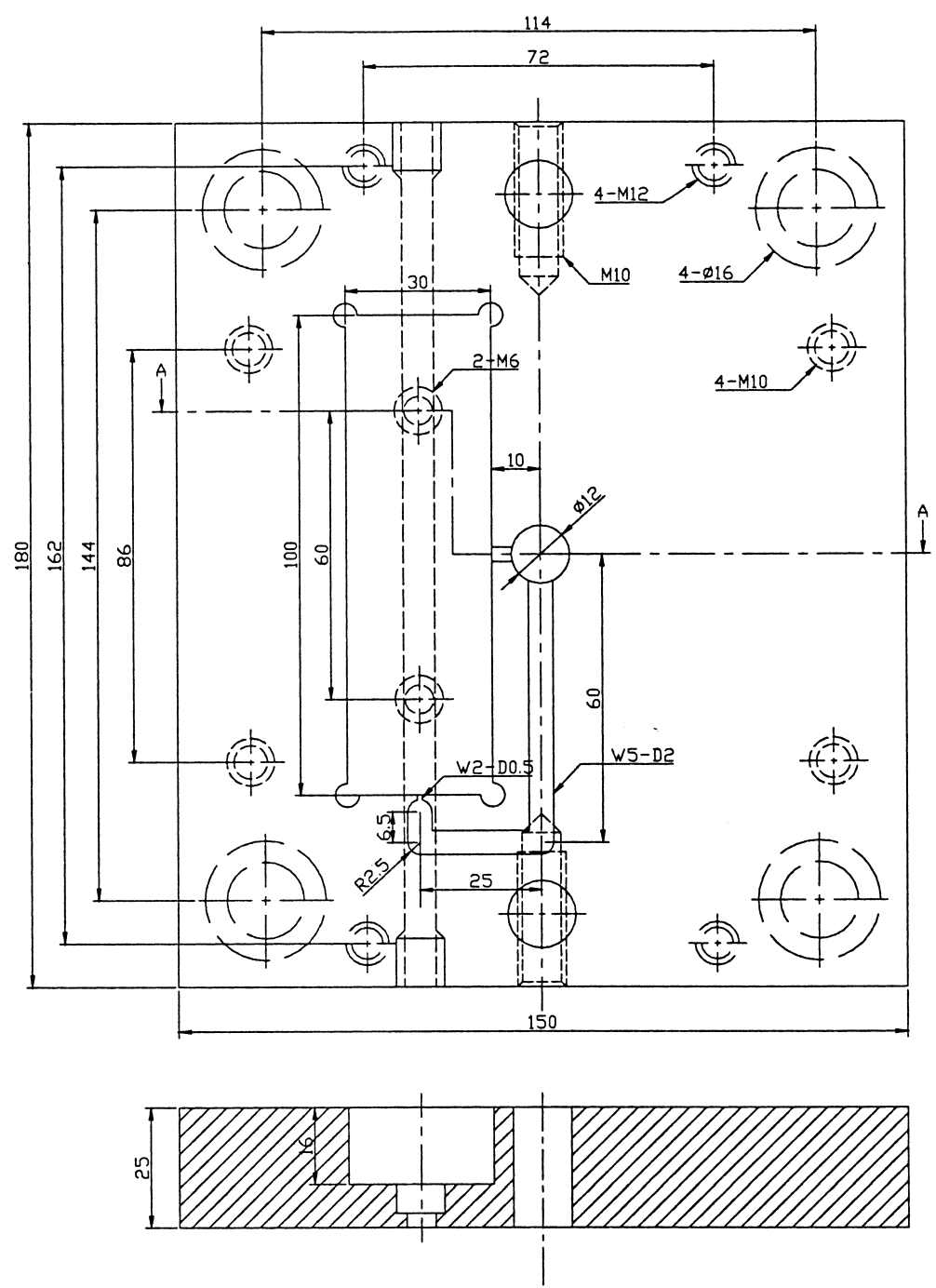

(a)

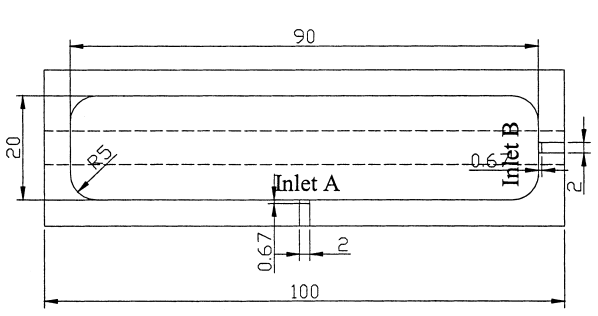

(b)

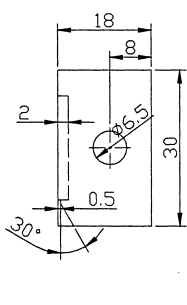

(Unit: $\mathrm{mm}$ )

FIGURE 5. (a) The geometry of the stationary mold plate, (b) The geometry of the insert for the stationary mold plate.

- Injection pressure: $17 \%$ of maximum injection pressure

- Injection speed: $20 \%$ of maximum injection rate
- Mold temperature: $50^{\circ} \mathrm{C}$

To evaluate the shear rate of sheet deformation, the finite element software MOLDFLOW (Mold- 

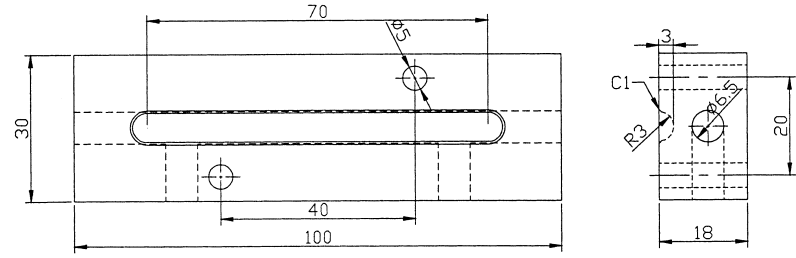

FIGURE 6. The geometry of the insert for the movable mold plate for molding plates with rib depth in $3 \mathrm{~mm}$.

flow, USA) is used to simulate pressure distributions during the filling of the plate cavity with rib. Meshing is designed to render best efficiency with reasonable resources.

\section{DEVELOPMENT OF MOLDABILITY DIAGRAM}

Moldability diagrams help justify the accessibility of the process. If the process is difficult, the molding area would be very small, or even nonexistent. Furthermore, molding areas allow one to optimize the mold design by comparing molding areas of different designs. The first step of construction of a moldability diagram is to choose the two most sensitive processing parameters among all processing parameters. The sensitivity of effects of injection speed, melt temperature, and injection pressure on part quality are compared; two of them will be chosen as critical parameters. The determination of critical parameters is based on comparing the molding ranges of processing parameters. A series of experiments derived from an experimental layout based on an L9 orthogonal array (as shown in Table I) of the Taguchi Method ${ }^{18}$ are also carried out for examining the effects of different processing parameters on quality for confirmation.

After two critical parameters are identified and confirmed, a series of SIM experiments will be performed by changing one of these two parameters with all others fixed. The quality of each part is examined. Satisfactory quality is defined as a plastic part completely filled without any fracture on the surface of the $\mathrm{Zn}-\mathrm{Al}$ sheet. The molding area is then plotted on the plane of these two key parameters. Moldability diagrams are then used to compare the SIM systems for various sheet thicknesses. The effects of melt-inlet location are also investigated by comparing the moldability diagrams.

\section{Results and Discussion}

\section{SHEET DEFORMATION DURING MOLD FILLING PROCESS}

Figure 7 shows the top view of the melt front profiles with various short-shot weights along with the side view of sheet deformation profiles. It can be noted that the melt front profiles are straight with little leading in the central rib zone. This is different from the flow pattern seen in filling a cavity with a ditch in the center. Significant leading in the center is always observed due to a racetrack effect. Even

TABLE I

An Experimental Array Based on the L9 Table

\begin{tabular}{lccccc}
\hline & $\begin{array}{c}\text { A } \\
\text { Sheet Thickness } \\
(\mathrm{mm})\end{array}$ & $\begin{array}{c}\text { B } \\
\text { Melt Temp. } \\
\left({ }^{\circ} \mathrm{C}\right)\end{array}$ & $\begin{array}{c}\text { C } \\
\text { Inject. Pressure } \\
(\%)\end{array}$ & $\begin{array}{c}\text { D } \\
\text { Inject. Speed } \\
(\%)\end{array}$ & Results \\
\hline L1 & 0.15 & 180 & 17 & 20 & Incomplete rib \\
L2 & 0.15 & 210 & 28.4 & 50 & Sheet fracture \\
L3 & 0.15 & 240 & 39.7 & 80 & Sheet fracture \\
L4 & 0.2 & 180 & 28.4 & 80 & O.K. \\
L5 & 0.2 & 210 & 39.7 & 20 & Sheet fracture \\
L6 & 0.2 & 240 & 17 & 50 & Sheet fracture \\
L7 & 0.25 & 180 & 39.7 & 50 & Sheet fracture \\
L8 & 0.25 & 210 & 17 & 80 & O.K. \\
L9 & 0.25 & 240 & 28.4 & 20 & Sheet fracture \\
\hline
\end{tabular}




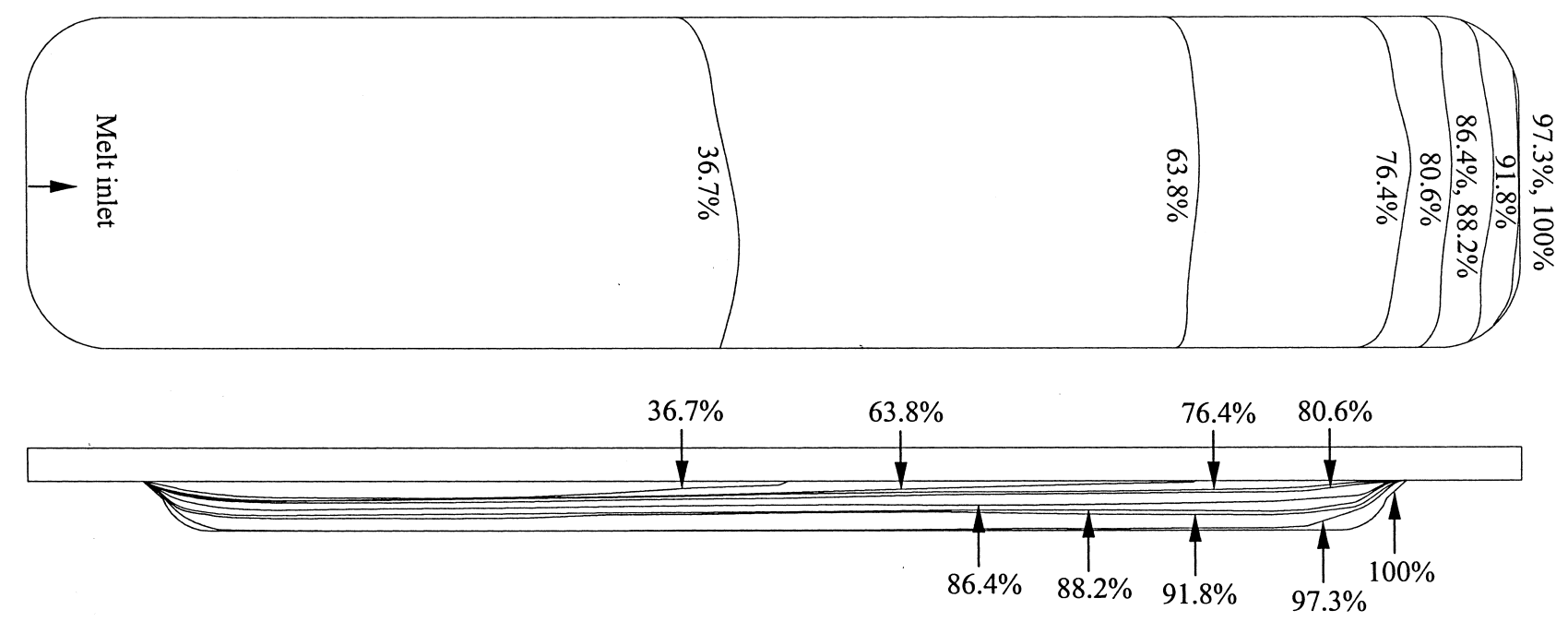

FIGURE 7. Series of short-shots showing the profiles of melt front (top view) and sheet deformation (side view) during cavity filling of SIM process.

though the $\mathrm{Zn}-\mathrm{Al}$ sheet is deformable, little deformation takes place during the initial cavity filling stage. This phenomena is confirmed in the side view showing sheet deformation profiles. Though the tips of sheet deformations in the rib zone always lead the melt front, the sheet deformation is small. In fact, the depth of sheet deformation in the rib zone never exceeds $50 \%$ of rib depth until $80 \%$ of short-shot weights are injected.

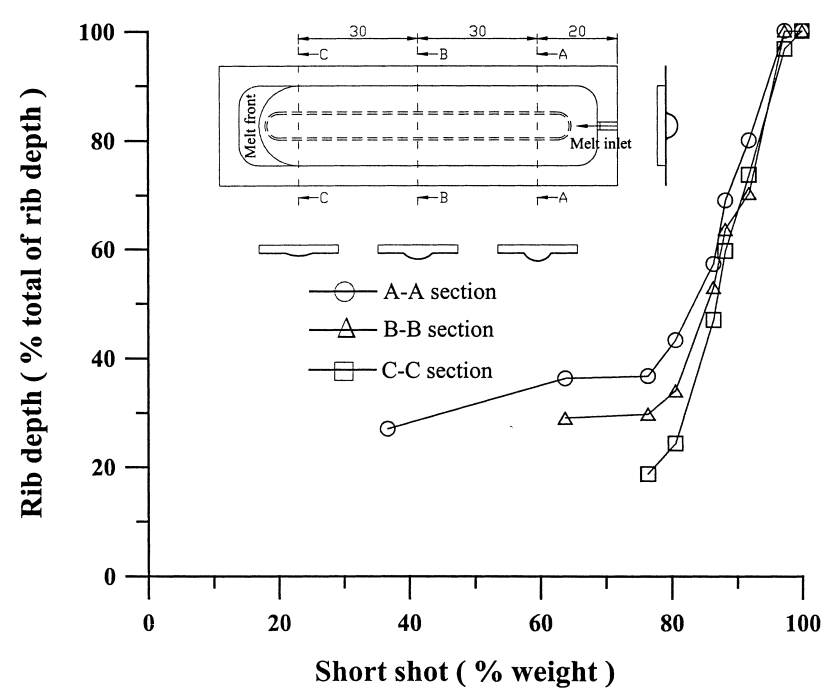

FIGURE 8. The evolution of rib depths at three sections as functions of short-shot weight percentages, showing that most sheet deformation occurs during the final stage of cavity filling.
Figure 8 depicts the depths of sheet deformations in sections $\mathrm{A}, \mathrm{B}$, and $\mathrm{C}$ observed in short-shot experiments. As can be seen, deformed rib depths are minor when short-shot weights are $<80 \%$; deformed rib depths increase rapidly after $80 \%$ of short-shot weights are injected.

The SIM filling process could thus be divided into two stages. The first filling stage is mainly for the cavity filling (to fill up to $80 \%$ of the cavity). The second filling stage is for both the cavity filling (to fill the final $20 \%$ of the cavity) and sheet deformation (to form $>50 \%$ of the sheet deformation in the rib zone).

Figure 9 presents the pressure profile calculated with finite-element software MOLDFLOW at sections $\mathrm{A}, \mathrm{B}$, and $\mathrm{C}$ during the cavity filling process. As the melt passes these sections, pressures rise during the remaining filling stage. In the beginning stage of filling, low pressure results in limited sheet deformation. Nevertheless, pressure rises sharply in the final stage of filling and significant sheet deformation is observed. Pressure reaches maximum during packing and sheet deformation in rib sections is completed. The average shear rate of the sheet deformation at any instant can be calculated by:

$$
\dot{\varepsilon}=\ln \frac{l_{2}}{l_{1}} / \Delta t
$$

where $l_{2}$ and $l_{1}$ are the lengths of two neighboring 


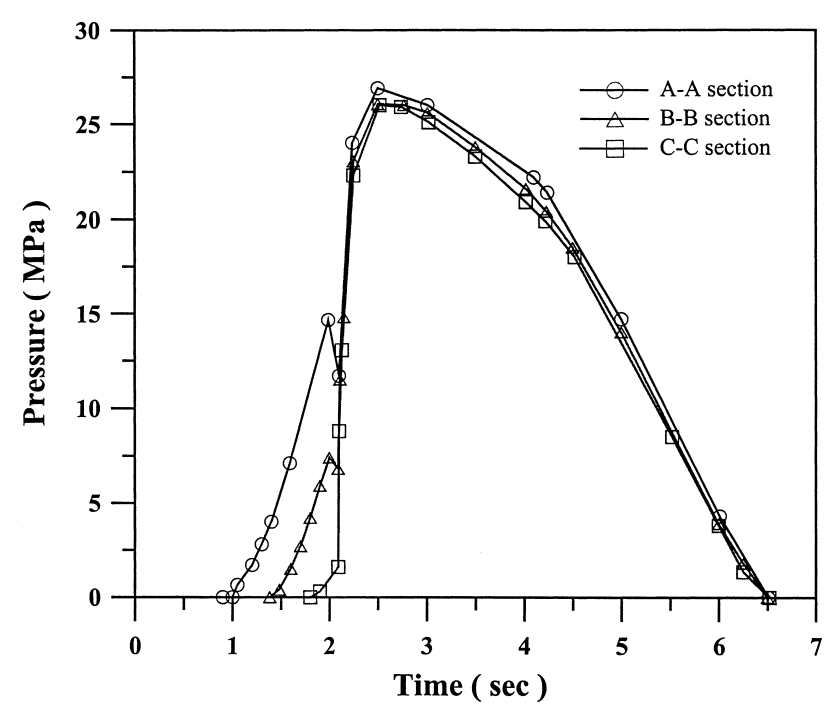

FIGURE 9. Pressure profile vs. the filling time at three sections simulated by MOLDFLOW. Pressure increases rapidly as plastic fully fills the mold.

points after a time interval $\Delta t$. The shear rate at various times, as shown in Figure 10, can be calculated using Eq. (1) based on the measured displacements in Figure 8. The shear rate during cavity filling is shown. High shear rates appear in the final stage of filling. For the initial filling stage, the shear rate is low; however, the shear rate increases rapidly for the sheet deformed at the final filling. The maxi-

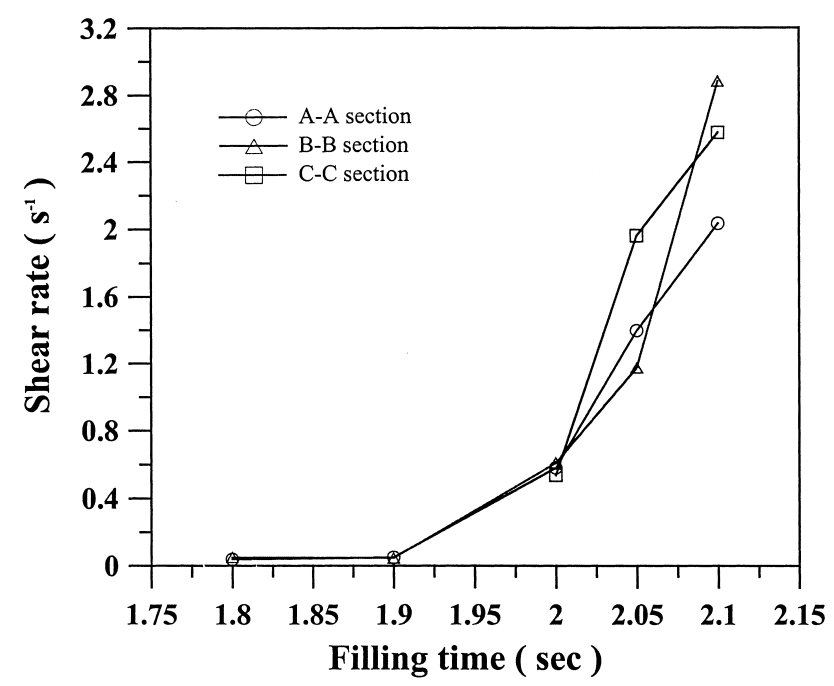

FIGURE 10. The shear rate at three sections as functions of filling time showing that the sheet deformed rapidly in the final stage of filling. mum shear rate is about $2.88 \mathrm{~s}^{-1}$ at section $\mathrm{B}$. This rate lies in the upper bound of shear rates in conventional superplastic forming, which is $10^{-1} \sim 10^{-3}$ $\mathrm{s}^{-1} \cdot{ }^{10}$ Because only limited deformation is needed, the $\mathrm{Zn}-22 \% \mathrm{Al}$ sheet can be formed with this shear rate.

\section{RELATIVE SIGNIFICANCE OF PROCESSING PARAMETERS}

Figure 11 shows the molding ranges of injection speeds with specific combinations of injection pressure and melt temperature for successful molding. The so-called "successful molding" is defined as the plastic part completely filled without any fracture on the surface of the sheet. With melt temperature at $260^{\circ} \mathrm{C}$ and injection pressure at $11.3 \%$, successful molding can be obtained with the injection speed control set between 20 and $80 \%$. On the other hand, with the same melt temperature $\left(260^{\circ} \mathrm{C}\right)$, the molding range of injection pressure control for successful molding is $6 \sim 11.3 \%$, with the injection speed fixed at $20 \%$. Therefore, the injection pressure control is more sensitive than the injection speed control. Melt temperature is another sensitive processing parameter. When the melt temperature is lowered to $160^{\circ} \mathrm{C}$, the molding range for the injection speed control is reduced to $20 \sim 40 \%$. Injection pressure

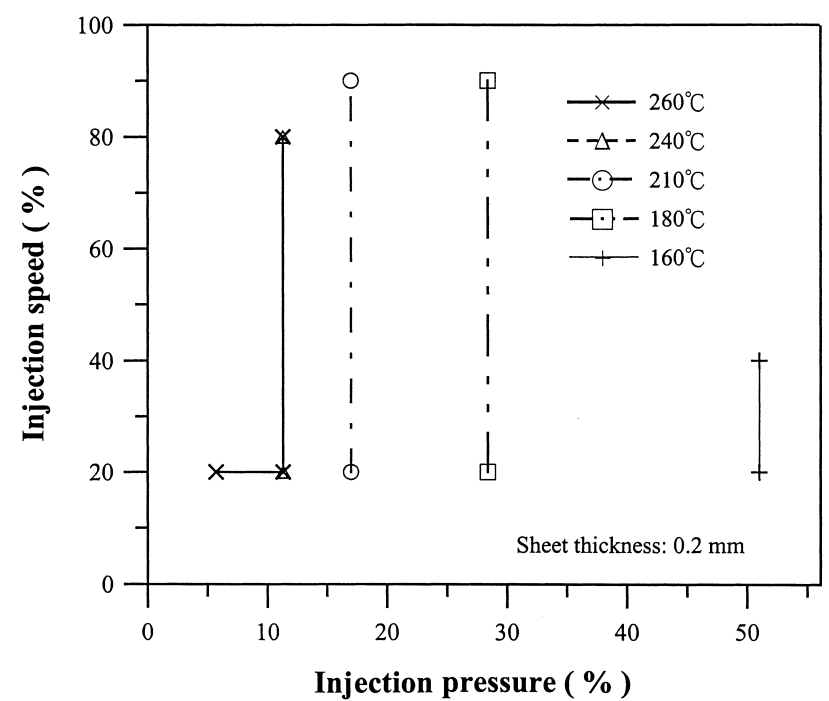

FIGURE 11. Moldability ranges of injection speed and injection pressure with various melt temperatures. Injection pressure control is more sensitive than injection speed control. 
and melt temperature are selected to be the most critical processing parameters.

The results obtained from a series of experiments based on an L9 array of the Taguchi Method shown in Table I confirm this selection. As can be seen, some successfully molded parts are processed with high injection rates (L3, L4, and L8), while others are processed with low injection rates (L1, L5, and L9). On the other hand, SIM moldings processed with high injection pressure or high melt temperature always result in sheet fracture; while low melt temperature and injection pressure can easily result in incomplete shots. Melt temperature and injection pressure are the two most critical parameters.

\section{MOLDING AREA BASED ON CRITICAL PARAMETERS}

The moldability can now be defined as ranges of melt temperature and injection pressure which yield successfully SIM molded parts. In the moldability diagram, as schematically shown in Figure 2, the processing parameters, $\mathrm{A}$ and $\mathrm{B}$, are melt temperature and injection pressure, respectively. Defect 1 is thermal degradation, defect 2 is sheet fracture, and defects 3 and 4 are incompletely molded parts.

Figure 12 shows the molding areas of SIM systems with inlet A for four different sheet thicknesses. As shown in Figure 13, the SIM system of $0.3-\mathrm{mm}$ sheet thickness (marked with triangles) has the largest molding area among all SIM systems.

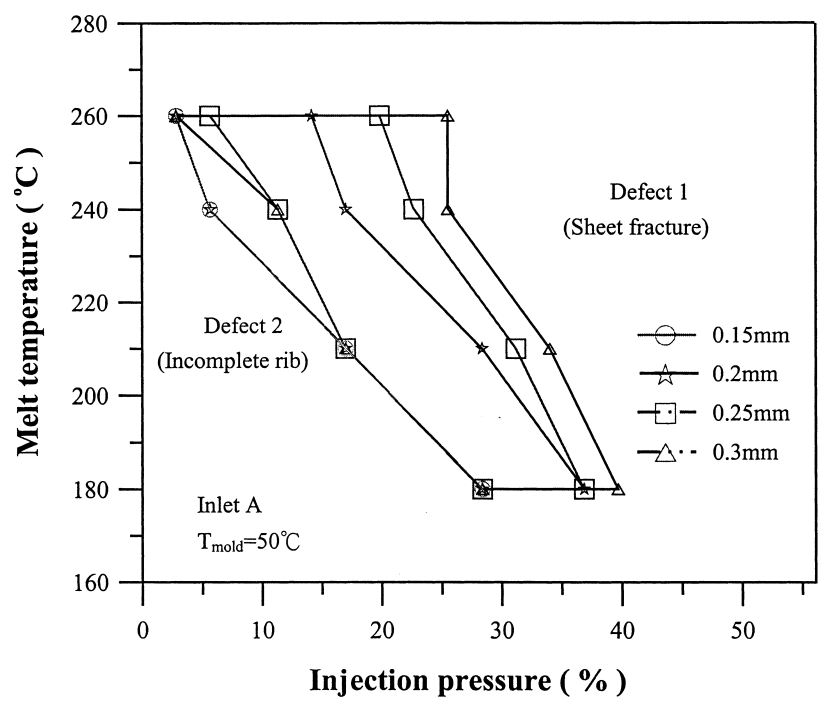

FIGURE 12. The moldability diagrams of various SIM systems for inlet A (center gate).

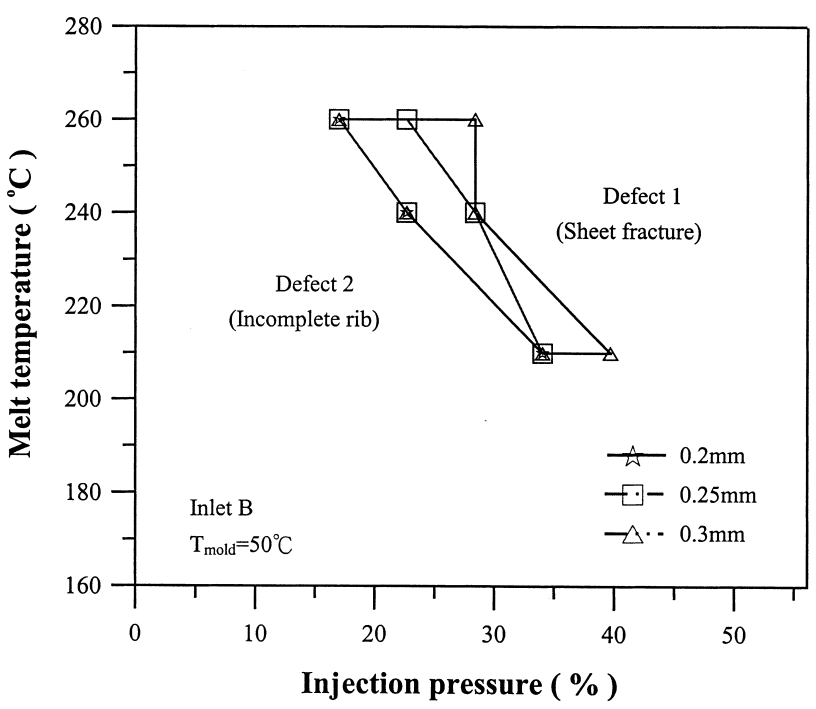

FIGURE 13. The moldability diagrams of various SIM systems for inlet $B$ (end gate).

This implies that a thick sheet improves moldability. From the shapes of the molding area, it is noted that the higher the melt temperature, the wider the molding ranges of injection pressure. This implies that a high melt temperature improves moldability.

Figure 13 shows the molding areas of SIM systems with inlet B. All the molding areas for SIM systems with inlet B are smaller than those with inlet $\mathrm{A}$. This indicates that an inlet providing short flow length improves moldability.

\section{Summary and Conclusions}

This research explores the basic process characteristics of superplastic injection molding. With this new process, superplastic $\mathrm{Zn}-\mathrm{Al}$ sheets can be formed by the plastic melt during cavity filling to provide a conductive metal surface to plastic plates with ribs. The fundamental process phenomena, such as the process of sheet deformation during cavity filling, are observed with the aid of short-shot experiments. More than half of the sheet deformation is found to occur during the final $20 \%$ of cavity filling. The final filling stage provides the higher shear rate to form the sheet. As far as moldability is concerned, injection pressure and melt temperature are found to be the most critical parameters. The concept of the moldability diagram has been ex- 
tended from conventional injection molding to superplastic injection molding. The moldability diagram based on melt temperature and injection pressure is defined and employed to compare moldability of different systems. A short flow length, thick superplastic sheet, and high melt temperature are found to improve moldability.

\section{Acknowledgements}

The authors would like to express their thanks to the National Science Council and Industrial EMI consortium of Taiwan, ROC, for financial support; to professor T. H. Chuang of National Taiwan University for organizing the research team and initiating the idea of SIM; to professor C. F. Yang of TaTung University for the supply of $\mathrm{Zn}-\mathrm{Al}$ sheets; to coworkers in the Grace Laboratory for Polymer Processing for stimulating discussion and experimental assistance; and to POLYPAX Machinery Company for help in machine acquisition and modification.

\section{References}

1. Hamilton, S. New Elect 1987, 28(4), 22-23.

2. El-Amin, H. Plast Techn 1981, 27(9), 67-72.
3. Crossman, R. A. Polym Eng Sci 1985, 25(3), 507-513.

4. Bigg, D. M. Polym Eng Sci 1979, 19(16), 1188-1192.

5. Markstein, H. W. Elect Pack Prod 1984, 24(9), 132-136.

6. Higuchi, K.; Nakajima, K. Proceedings of the IEEE Intern Symposium on Elect and the Environ, 1996; pp 102-108.

7. Kimura, K.; Nishi, K.; Ishizuka, M.; Miyahara, S. The Sixth Intersociety Conference on Thermal Phenomena, 1998; pp $35-42$.

8. Furukawa, M.; Horita, Z.; Nemoto, M.; Valiev, R. Z.; Langdon, T. G. Mater Sci Eng 1998, A241(1), 122-128.

9. Underwood, E. E. J Met 1962, 14(12), 914-919.

10. Sherby, O. D.; Wadsworth, J. Prog Mater Sci 1989, 33(3), 169221.

11. Lanvers, A.; Michaeli, W. SPE ANTEC Tech Paper, 1992; p 1796.

12. Zheng, T.; Koskey, J.; Altan, T. SME Tech Paper, 1993.

13. Yamamoto, K.; Harada, K.; Okada, Y. PPS Regional Meeting, 1994; p 218.

14. Yang, S. Y.; Liou, S. J.; Liou, W. N. Adv Polym Techn 1997, 16(3), 175-183.

15. Yang, S. Y.; Liou, S. J. Adv Polym Techn 1995, 14(3), 197205.

16. Tadmor, Z.; Gogos, C. G. Principles of Polymer Processing; John Wiley \& Sons: New York, 1979; pp 590-591.

17. Mohamed, F. A.; Ahmed, M. M. I.; Langdon, T. G. Metall Trans A 1977, 8A(6), 933-938.

18. Chang, G. W.; Lo, S. Y.; Soun, G. C. Society of Quality Control; Taipei, Taiwan, 1992, p 182. 